\title{
The Physical Environment of Early Childhood Centers: A Case Study in the use of Break-Out Spaces
}

\author{
Elizabeth Matthews ${ }^{1}$, Peter C. Lippman ${ }^{2}$ \\ ${ }^{1}$ City College, City University of New York, USA \\ ${ }^{2}$ EIW Architects, Perth, Australia
}

\begin{abstract}
The creation of high quality Early Learning Centers is at the top of the national agendas in nations around the globe. Historically, changes directed towards improving Early Childhood Education have focused on the aspects of the social environment and curriculum. While these factors play an important role in early learning center quality, we find that too little attention is given to important role of the physical setting of the classroom. Despite the fact that there is a near 50year history of documented evidence on the impact of physical parameters on children's learning and development, few policies or interventions are specifically directed towards making systematic improvements to the built environment. We find this especially problematic given that the physical environment of classroom can impact the language, cognitive and social development of children in significant ways. In this case study, we provide a review of the most salient research on the impact of the physical environment in Early Childhood and present examples of how the use of Break-Out Spaces can effectively address physical aspects of the classroom that impact children's learning and development.
\end{abstract}

\section{Introduction}

Early Childhood Education (ECE) is at the forefront of national agendas around the world. Political leaders, educators, policy makers and parents, are eager to improve the quality of, and access to, Early Childhood Education. This call to action is based largely on the robust and rarely disputed body of evidence that consistently demonstrates that children who attend high quality early care settings benefit significantly both in the short and long term [1]. Among the most commonly cited findings are that children who are educated at very young ages in high quality centers are able to perform at a higher academic level, engage more appropriately with peers and authority figures, have a lower risk of incarceration, and have a greater chance of finishing high school and attending college, than young children who do not receive quality early educational experiences [1]. Beyond the individual benefits, many experts have proposed that society as a whole stand to gain from investments in early childhood education through the reduction of poverty, greater employability and improved social mobility. In fact, in economic terms, it has been suggested that for every dollar invested in early childhood education, the return on that investment is nearly threefold. It is important to recognize however, that such gains have only been born out when children attended "high quality" early learning centers [2].

Over the last few decades there has been a great deal of investigation into what makes a "high quality" early childhood learning environment, and as a result many policies and legal mandates are designed to improve these aspects of quality. To date, the majority of research and subsequent policy is related to social and curricular aspects of early education. For the most part, quality centers generally have highly trained, professional teachers, low teacher: student ratios, high parent involvement, consistent daily schedules of activities and a developmentally appropriate curriculum that centers on the needs of the students [3]. Undeniably all of these elements are critical to the development of high quality preschool education, however, we argue that an important aspect of the ELC has been long neglected - the built environment of the classroom.

It is clear that the physical setting of the ELC has a significant impact on young children's developmental trajectory and well-being. Dating back to the early 1980's there has been a convincing body of evidence from the field of environmental psychology field that purports that the physical setting and structures within where children learn, have a unique and powerful influence on their learning and development. Far from being merely a "backdrop" for social action to occur, the physical environment exerts influence on those within its walls. Poorly designed spaces often result in high levels of environmental chaos, which can have deleterious impacts in the classroom for example, noise, crowding and poorly designed spatial layout of a classroom can negatively impact children's learning, social interactions and contribute to the experience of stress. Furthermore, these environmental factors exert a negative influence on teacher behavior including, but not limited to a 
decrease in the quantity of verbalizations with students. [4]. Unfortunately, the environmental attributes of the educational setting are not often prioritized when policy decisions are made.

Accordingly, the argument can be made that investment in the built components of a classroom are critically important when assessing the quality of a learning environment. In this paper, we discuss the use of Activity Settings and Break-Out spaces, which we propose can reduce many of the aspects of the physical environment that can lead to undesired development outcomes. Activity Settings are differentiated learning zones that are located inside the classroom, whereas Break-Out spaces are defined spaces often fixed outside of or adjacent to the classroom. These spaces promote highly defined areas for learning activities as well as needed shelter from overstimulation and/or a spot for quiet individual or small group activity. Well-designed spaces can provide needed variety and an optimal physical setting for learning, while providing needed control of factors that are associated with environmental chaos. In the following sections we present the existing literature on the impact of the built environment on children's development and present two case studies that illustrate how BreakOut spaces were conceptualized and employed in ELC settings.

\section{Physical Environment and Childhood Development}

A primary focus in Environmental Psychology is to achieve an understanding of the constraints and affordances of the physical setting and how these mold, affect, and support well-being. Since the field's conception nearly a half century ago, environmental researchers have found that some of the most important aspects of the built environment found to significantly impact the developing person include: spatial design, noise level, degree of crowding and amount of light [4]. These particular qualities are believed to influence the learner because, poorly designed layouts, high levels of noise and crowding and inadequate lighting result in environmental chaos. Unchecked disorganization in the built environment can affect, in a very negative manner, children's ability to focus and engage in learning. A chaotic environment can also contribute to physiological and psychological stress that can negatively affect children's social interactions as well as the ability to effectively participate in the school day. It is also important to note that the same environmental inadequacies can negatively impact teachers' responsiveness and engagement.

While none of these findings are new, much of them, for a variety of reasons, appear to be relegated to secondary status to that of the social variables [5] of teaching and learning. For example, when parents and teachers of an Australian ELC were interviewed regarding their perspectives on important components of early learning, the majority commented that aesthetically pleasing, well-planned environments were beneficial and highly desired in the ELC, but were secondary to teaching quality. Furthermore, neither educators or parents were able to identify the specific ways in which the physical setting contributed to teaching quality or the child's educational experience as a whole. [5] Thus the reigning belief about the inferiority of the built environment appears to be derived in part from a lack of understanding about the ELC research in environmental psychology. However, there is also a recognition that that people largely control the design of their own environments; therefore, it is the social actions that shape human interactions within a space. Conversely, Environmental Psychologists, suggest that it is the physical space that mediates our social transactions. This is believed to occur by way of a variety of direct and indirect impacts on specific aspects of growth and development as well contributing to molding the sense of self [6]. Aside from the mediating effects, in certain cases it may prove difficult, if not impossible to easily control certain environmental variables. Noisy construction sites may appear next to schools without significant warning and limited budgets may force school builders to build schools or classrooms in places or ways that do not adequately allow for the control of negative environmental variables.

Recently researchers in the UK examined a number of specific environmental parameters present in classrooms [7]. Based on the analysis of the data, they were able to attribute $51 \%$ of learning variability to aspects of the built environment among school-aged children. The most significant components of the built environment appear to be complexity, availability of choice, color, naturalness, and lighting. These elements accounted for the most significant variations in academic performance measures [7]. Many basic aspects of the structural setting of a school can alter students' cognitive processes [8]. Thus, environmental complexity, light, and quality of materials are not simply a matter of creating aesthetically pleasing environments, but also appear to have an impact on other cognitive and social processes essential for learning.

Other environmental characteristics such as levels of background noise as well as the acoustical conditions of the classroom can impact learning. Chronic levels of ambient noise are associated with the development of a stress response that can impair learning. Similarly, poor acoustical conditions have been found to reduce both learning comprehension and speech recognition in children [9]. However, presence of "white noise" may actually enhance learning activity by stimulating certain regions of the brain [9]. Lastly, noise levels may impact language 
and cognitive skills indirectly, as chronic noise may reduce the verbalizations among adults and children [11].

Crowding, which is perhaps the greatest factor in the development of "environmental chaos", also has significant impacts on health and overall functioning. This apparently holds true, regardless of ethnicity or culture. High levels of crowding are positively correlated with increased levels of interpersonal conflict, which can directly hinder social emotional development [12]. Indirectly, student learning is also affected as teacher time can become disproportionately dedicated to intervening in peer altercations.

The empirical evidence on the ways in which the built setting impacts behavior transactions are particularly startling. For example, crowding in the environment, or even poorly designed spatial layout of the classroom frequently results in increased peer conflict as students feel higher stress levels when these conditions are present. However, teachers also can be negatively affected by a substandard design. For example, teachers may feel the need to utilize more restrictive practices with classroom management if they are teaching in settings that lack adequate spatial layout to allow for needed visual surveillance of students [13]. Thus, layout and design of the ELC are strong contributors to students' ability to independently engage and interact with classroom materials in an effective way.

When considering the powerful effects of the physical environment on learning, it is important to understand that just as poorly designed environments can have a deleterious impact on children's development, optimally built settings can exert a restorative effect on behavior and learning. For example, adding "green- ness" or nature into classrooms by including either easy access to the outdoors or incorporating plant life directly into school spaces improves children's attention and focus with tasks. Finally, the presence of stimulus shelters - a concept proposed by Environmental Psychologist Theodore Wachs in the 1980s can prove highly beneficial for children's development and psychological well-being. These "shelters" are areas where students can escape activity for brief periods of time. When incorporated into the design of a classroom, this particular feature has been shown to be beneficial for children's sense of wellbeing. [19]

Ultimately, the physical environment of the classroom should fulfill the students' and teachers' needs to enable learning. In our view, a welldesigned classroom that reduces environmental chaos is a basic requirement for a quality ELC. Once these essential needs are met, children and teachers are more likely to be in a stronger position to fulfill higher-level learning goals.

\section{Activity Settings and Break Out Spaces: The Importance of Differentiation of Space}

In order to effectively afford opportunities for optimal learning experiences inside and outside the classroom, an Early Childhood Learning Centre (ELC) must be purposefully designed to support independent, one-to-one and small social groupings of children [8]. In ELCs, classrooms should be created based on the research on the built environment and its relationship to child development and learning. Optimal learning environments are often highly differentiated spaces because they provide robust environmental complexity. In this paper, we refer to the distinct and differentiated learning areas of the classroom as "Activity Settings", and the fixed spaces located outside of or adjacent to classrooms, as "Break-Out Spaces". Both Activity Settings and Break-Out Spaces are learning zones that should be planned to afford independent, one-to-one, or small social groupings of 3-6 children who can work inside or outside of the classroom room [15].

In the educational realm, the Activity Settings of an ELC classroom are traditionally known as "learning centers". They commonly include block, reading, writing, math, science and creative play areas. Lastly, all Activity Settings and Break Out spaces must be fit with suitable technologies and resources to support the intended learning by way of:

- providing access to a variety peers with varying levels of skill with a given activity

- influencing the types of [transactions], verbal and otherwise, that occur in the daily routine

- affording learners spaces to actively explore the allowable range of activities permitted in the classroom space

- providing opportunities for students to create, reflect on, and redesign their activities and respond to their selfgenerated changes

- affording appropriate levels of adult direction and monitoring in order to allow for developmentally appropriate latitude in what children do and how they do it [14]

- $\quad$ reducing the potential for environmental "chaos" including crowding and noise via minimizing the impact of negative environmental features, while offering the developmental benefits of ideal built spaces. 


\section{Break-Out Spaces Defined}

Break-Out spaces are defined learning areas located outside of, or adjacent to classrooms. Although not studied extensively, the use of Break Out spaces can promote improved student learning and well-being by: 1) informing learners of where and what particular transactions are suitable in these areas 2) reifying the notion that learning is not confined to a space, but rather can extend beyond the walls of the classroom and 3) affording additional classroom space flexibility for teachers and students. Break-Out spaces can be particularly useful design elements. Depending on the size of the space, they are classified either as Break-Out Rooms, Hollows, Niches and Nodes [17] [18], which are each defined below.

Break-Out Rooms: These are semi-private small meeting or project rooms approximately 10 square meters. These spaces are generally planned to support 1-6 learners and can facilitate independent, one-to-one and cooperative social groupings. Most importantly, these learning zones allow learners to separate themselves from the larger class and focus on the specific task-at-hand. Frequently the BreakOut rooms are designed as fully enclosed spaced that are located within the classrooms or constructed outside of the classroom [17].

Break-Out Niches: Similar to the Break-Out Room, Break-Out Niches are semi-public learning areas that are designed to provide opportunities for formal and informal spontaneous interchanges. A Break-Out Niche may be a corner, recess or alcove along the walls inside a classroom or along a school hallway. Niches differ from the Break-Out Room because they are literally carved out spaces in already existing furniture or walls. For example, a hallway may have a hollowed out area that includes a chair and table. This structure allows classes to extend learning opportunities beyond the classroom. Within these differentiated learning areas, learners can work independently as well as in small groups. Furthermore, these spaces may provide opportunities for a few small social groupings to work simultaneously adjacent to one another [16] [17]. Constructing a Break-Out Niche could involve building recesses/alcoves/corners in the walls outside of classrooms or along school hallways.

Additional differentiation of the Break-Out Space can be accomplished with Break-Out Hollows. These areas can be designed into an existing niche. For example, a Break-Out Hollow can be a learning zone built into cabinetry, such as a seat for one for one learner, or a small opening in a wall or cabinet. Generally, given their small size, Break Out Hollows support independent work.

Break-Out Nodes: When installed optimally, these Break-Out Nodes can become the salient feature of the school setting around which breakout rooms, niches, and hollows may be organized. [17] These are public areas located as the center of the ELC school. For example, the Nodes might be constructed under a central school staircase.

This type of space promotes opportunities for independent, one-to-one, small group and large group engagement to occur simultaneously. This learning zone is unique, because its centralized location within the school building supports both formal and organized gatherings for more than one classroom, so that learning can take place among multiple classrooms and age groups. These spaces can also encourage a range of informal and spontaneous interchanges among parents, school staff and children during the transition points of the school day.

Perhaps most importantly, the inclusion of the Break-Out Space may aid in the effective control of environmental chaos and can reduce ambient noise levels, both of which have been noted to negatively impact student learning. These smaller places can create needed environmental complexity and reduce crowding levels by providing a variety of learning zones. Although students may be set apart from the main activity area, they can still be involved in the classroom activity if the space is designed appropriately. For example, spaces with glass within walls or doors allow for visual contact between students and teachers. This in turn can allow teachers greater flexibility as they can support independent and small group work, enhancing student freedom with learning activities, while still providing visual surveillance over all of these learning areas. Furthermore, anxiety levels in very young students can often be mitigated by enabling children with a learning setting where they can easily "check in" visually with their teachers.

Lastly, students can use Break-Out Spaces as a "stimulus shelter" [19], thus providing learners with a secure setting for needed refuge in order to counteract the effects of stress during the school day. If children are able to take advantage of independently arranged brief periods of rest throughout the school day, they may be in a better state to learn, socially engage and perhaps even, handle conflicts with others.

\section{Designing Activity Settings and Break- Out Spaces}

Activity Settings and Break-Out Spaces must be designed as integrated places within the ELC to support the diverse ways that children transact with one another and their environment to produce learning. In addition to providing a variety of developmentally appropriate Activity Settings, the classroom space as a whole must afford opportunities for large group meetings, small group work, and independent learning. While Activity Settings are 
viewed as separate learning areas, they in fact provide the classroom with an integrated learning experience. For example, Activity Settings provide spaces for children to learn within the defined area and also provide learning areas in between each defined space. [18]. These spaces-in-between allow learners to seamlessly transition from one task to another as they can move from their initial setting to another and/or simply stop to peruse the actions of others. This particular setting allows learners to appropriate knowledge without disrupting the flow of the transactions taking place.

In the ELC, the use of defined Activity Settings encourages learners to move about space and to become either independently engaged in a learning opportunity or to collaborate in the activities of others. Attractively designed spaces can peak children's interest among multiple areas of the classroom so that the learner is never discouraged from moving about the space, affording various opportunities for the rich kinesthetic experiences that are critical for young learners [18].

Accordingly, when planning instructional spaces, designers must consider the potential choreography through and around the Activity Settings and how these interstitial zones provide opportunities for learning. The spaces in between should be crafted in such a way as to promote easy movement among the classroom areas without leading to bottlenecking which can lead to disengagement and potentially peer conflict [18].

An important distinction in the purpose of Activity Settings and Break-Out Areas is that while Activity Settings are choreographed to encourage movement, Break-Out Spaces are often planned to disrupt movement and contain learning to enclosed areas to allow for enhanced focus on the task. In addition, the Break -Out Space often installed outside of classrooms or in school hallways offers the benefit of a "stimulus shelter"-places of respite where learners may become engaged independently with work, or simply relax. Both types of spatial arrangements create needed differentiation of the classroom space and can ameliorate many of the negative effects of excessive noise and crowding.

In the following section we present two case studies where Break-Out Spaces were used to enhance the layout of the ELC classrooms, reduce environmental chaos and negative environmental factors and improve the general flow of movement for teachers and students.

\section{Case Study 1 - Holy Cross College Early Learning Centre, Perth, Australia}

The Early Learning Center (ELC) at Holy Cross College in Perth Australia educates 180 children ages 3-6. The school's leadership team engaged EIW architects to re-design the ELC in early 2013. This re-design was part of their master plan for expansion of their learning community. The approach to creating this ELC was unique because the design team in collaboration with the teachers and students, grounded the classroom and school design in the existing research on early learning environments.

Each of the Holy Cross College ELC classrooms were planned to support six distinct activity settings: a block corner; a painting corner; an area for creative play, reading corner; science area, and reflective area. In order to differentiate the various learning areas, built-in cabinetry was used to separate the reading and block corners, a trough was placed near the toilet room to create an art area. Pin boards were placed over the cabinetry, and idea paint (vertical writing surfaces) was used as a finish on different wall locations in the rooms. Moveable child sized tables and chairs, as well as soft seating were used to further define the areas between the corner settings. These built-in physical cues in the classrooms, enabled teachers and students to organize their surroundings as needed. Lastly, the activity settings were organized to allow learners and teachers easy visual access throughout the classroom.

These purposeful choices within the classrooms resulted in the creation of spaces that were highly differentiated while at the same time connected the ELC classrooms to one another, in order to create an integrated learning environment for the entire school building. These specific design choices were made to promote opportunities for independent and small group activities and improve the flexibility of the space. For example, utilizing cavity sliding doors rather than folding walls, between classrooms afforded multiple benefits. Cavity sliding doors provide significant flexibility for classroom. [15] [18] Teachers can easily install or remove the partition, depending on their needs. Such flexibility allows teachers to take ownership of their classrooms. They can choose, at any time, to connect classrooms and extend the classroom to the BreakOut Spaces, or manipulate the cavity sliding doors to easily disconnect rooms from the Break-Out Spaces to afford for more personalized and specialized learning opportunities. Although cavity sliding doors can be heavy to manipulate, they offer the added benefit of sound insulation that can significantly improve the acoustic conditions within the classroom.

Following discussions with the principal and teachers, the design team planned to install a variety of Break-Out Spaces designed to add differentiation and flexibility for the ELC classrooms. These included a Break-Out Room as well as several Break-Out Niches placed outside of, and attached to each classroom. Cabinetry was designed with open shelving and was used to define the spaces created within the Break-Out Niches and Node. Lastly, a Break-Out Node was placed centrally in the building. 
Placing this Node at the heart of the school building was done to facilitate learners, educators and parents to meet informally with each other as they move from one part of the school building to another. Ideally, such a space can encourage greater levels of personalization and socialization.

Throughout the ELC, customized cabinetry was purposefully included in order to afford further opportunities for learning. In the classrooms, cabinetry was used to define corner spaces. Doing so created corner spaces that more readily provided spaces for independent work or refuge for a rest [15]. They provide the added benefit of providing a vantage point for students to view and hear what is going on around them. Since the completion of the cabinetry project, teachers have reported that the cabinets provided excellent, concrete cues for children to seek out appropriate areas for independent or small group work.

Cabinetry was also integral for defining the Break-Out Niches and Node. Teachers have reported on how children have taken ownership of the various Break-Out Niches. Furthermore, the children uncovered Break-Out Hollows in and on the cabinets, where they have been observed sitting, reading, and talking with another. The centrally placed Break-Out Node was defined with tiered cabinetry where children could work, meet, play or rest. Additionally, moveable furniture, ottomans, tables and chairs were also provided in the Node, so that children could arrange or rearrange the space themselves, thus allowing for the development of a customized learning environment. The ability to exert control over the space can help learners experience greater autonomy in directing their own learning activities.

Finally, glazing was used along the perimeter walls, the demising walls, and sliding doors between the classrooms and the Break Out spaces. Natural light has long been shown to benefit learners and the glazing allowed for more natural light to enter all of the learning spaces [17]. Glazing also enables learners to see into other spaces and view the activities and actions of their peers and teachers [18]. Thus, the use of glazing can further personalize a space, encourage learners and teachers' connections with each other, and reinforce the unique culture of the learning environment.

At the Holy Cross College ELC, the design of the Break Out Spaces was created with the educational and spatial design research in mind. In this ELC greater classroom differentiation with the inclusion of Break-Out Spaces resulted in an environment that afforded learners and teachers with greater comfort, flexibility and learning potential.

\section{Case Study 2 - Skapaskolan, Huddinge Sweden}

Approximately 14,000 kilometers from Holy Cross College is the Skapaskolan ("creative school") in Huddinge Sweden. This school currently serves approximately 125 students, ages 4-12. In preparation for a new school building, the Skapaskolan faculty sought out educational design planning advice in order to change the current classroom designs to better reflect the school's alternative pedagogical approach.

In order to address the school's needs, it was necessary to conduct a thorough assessment of the school. Accordingly, teachers, administrators and students were interviewed and observed by the design team to better understand their concerns and needs as well as to offer objective assessment on the use of the current school space. Through the extensive interview and assessment process, it was discovered that the furniture and equipment in the rooms restricted the learners' capacity to move between and across different learning zones. Teachers wanted dynamic spaces that could afford a variety of independent and small group activities yet provide an efficient and engaging environment.

Based on the interviews and classroom observations, as well as the research in classroom design and child development, the classrooms at Skapaskolan were transformed from static to dynamic spaces. The furniture and equipment in the rooms were rearranged to allow the users to have a spaces where the class could meet in a large group and areas where they can meet in small cooperative groups. The large gathering space was defined with a 1.8-meter diameter rug. Tables and chairs were placed along the windows to create more independent work-spaces. Adjacent to these spaces, round tables with chairs and stools were added to the area in order to encourage small groups to gather. Moveable cabinetry was placed strategically to further define these areas and soft seating was used where children could sit next to each other and work independently, one-to-one, or in groups. Clear sight lines were established in the classroom so that teachers could easily view all the activities taking place from nearly any vantage point.

Similar to experiences reported by teachers at the Holy Cross College ELC, the teacher-reported benefits of adding defined and differentiated spaces at Skapaskolan have been numerous. Teachers have commented that the differentiated space enabled children to take greater ownership of the classroom. For example, students uncovered the Break-Out Hollows created by the natural space underneath round tables. Students used these areas to develop their own spaces for reading or small group discussion. The environmental changes created additional opportunities for learners to choose the 
physical spaces that best supported their learning needs at a given time. This was supported in the follow up interviews with staff, who noted that the Break- Out Spaces enabled learners to choose how and where they could best learn in a classroom even when a variety of other learning activities occur simultaneously. According to the teaching staff, students engaged with their learning with greater autonomy following the redesign of the classroom.

\section{Conclusion}

The physical environment of the early childhood classroom contributes profoundly to children's learning and social development. It is important that classrooms and their adjacent spaces are created with this research in mind. Unfortunately, evidenced based classroom design has not traditionally been at the forefront in the dialogue on educational quality. While parents, educators and designers recognize the need for bright, comfortable and flexible classrooms [5] most continue to view these elements as secondary to, and separate from, teaching and learning. Despite the current state of the science on the impact of the built environment, the physical setting has not yet found a central position in the current dialogue on quality early learning environments. This neglect stems in part, from a lack of appreciation for how place shapes the learner and the process of knowledge acquisition. As discussed throughout this paper, the physical realities, affordances and limitations of a classroom can greatly affect the social relationships among children as well as the transactions between teachers and students [8] [13]. Given the vast research on the impact of the built setting on teaching, learning and child development, we feel that it is necessary to bring the physical setting into a more central role in education. Accordingly, it is only fitting that we strongly consider targeting policies that are dedicated towards improving the quality of Early Childhood Education at the physical settings of classrooms and schools, as these may serve as unique vehicles for enhancing ELC quality.

Investing in the physical setting of the ELC need not always require significant construction or cost. We can tap into the powerful effects of the environment, in many cases, by making small changes to a classroom. In this paper we discussed the incorporation of Break-Out Spaces as potential ways with which to transform a classroom and the spaces outside into more dynamic learning zones. These distinct areas can promote the rich, environmental complexity needed to support learning, while adequately controlling a myriad of factors including crowding, noise, and poor layout all of which can negatively impact the cognitive and social processes so critical for young children's development. While the premise of our discussion of the use of Break-Out Spaces has been largely theoretical and limited by the presentation of only two case examples, it nevertheless brings to light the need to consider built aspects of classroom as strong contributors to ELC quality. Additional systematic research on the utilization of Break-Out Spaces should be conducted to further elucidate the associations among quality environmental design and children's learning.

\section{Acknowledgements}

We would like to thank: Holy Cross College for the continual support and openness to wanting to create learning environments that reach beyond best practice; EIW Architects for being academic and challenging the normative theories in Architecture on the spatial design of learning environments; and Skapaskolan for their desire to create and provide learners with the most innovative solutions within very confined spaces.

\section{References}

[1] W. T. Gorley "From Science to Policy in Early Childhood Education”, Science, 2011, pp 978-981.

[2] J. J. Heckman "The Economics of Inequality: The Value of Early Childhood Education", American Educator, 2011, pp 31-36.

[3] P. Slot, P.M. Leseman, J. Verhagen, \& H. Mulder. "Associations Between Structural Quality Aspects and Process Quality in Dutch Early Childhood Education and Care Settings", Early Childhood Research Quarterly, 2015, pp. 64-76.

[4] R.B. Bechtel, A. Churchman. Handbook of Environmental Psychology, Wiley, NY, 2003.

[5] R. Berris, E. Miller. "How Design of the Physical Environment Impacts on Early Learning: Educators and Parents' Perspectives". Australasian Journal of Early Childhood, 2011, pp.102-110.

[6] C. C. Marcus House as the Mirrol of Self: Exploring the Deeper Meaning of Home. Nicolas Hays, FL,1997.

[7] P.Barrett, Y. Zuhang, J. Moffat, K. Kobbacy. "A Holistic, Multi-level Analysis Identifying the Impact of Classroom Design on Pupils' Learning “, Building \& Environment. Building \& Environment, Elsevier, 2013, pp 678-689.

[8] P. A. Arndt "Design of Learning Spaces: Emotional and Cognitive Effects of Learning Environments in Relation to Child Development." Journal Compilation, International Mind, Brain, and Education Society, Blackwell Publishing, Inc. 2012, pp41-48.

[9] D. L. Valente, H.M. Plevinsky, J.M. Franco, E.C Heinrichs-Graham, and D, E. Lewis "Experimental 
Investigation of the Effects of the Acoustical Conditions in a Simulated Classroom on Speech Recognition and Learning", Annual Meetings of American Auditory Society, 2010.

[10] V. Rausch, E. Bauch \& N. Bunzek. "White Noise Improves Learning by Modulating Activity in Dopaminergic Midbrain Region and Right Temporal Sulcus", Journal of Cognitive Neuroscience, 2014267 1469-1480

[11] K.Mealings, Students Struggle to Hear Teacher in New Fad: Open Plan Classrooms http://mq.edu.au/newsroom/2015/02/10/students-struggleto-hear-teacher-in-new-fad-open-plan-classrooms/ \#ixzz3cKdmHsIZ. MacQuarie University, Sydney, Australia, Date 10 February 2015. Access Date: 20 June, 2015.

[12] G.W Evans, S.J. Kepore, K.M. Allen. "Cross Cultural Differences in Tolerance for Crowding: Fact or Fiction?", Journal of Personality \& Social Psychology,2000, pp 204210.

[13] S. Kritchevsky. \& E. Prescott. with L. Walling, "Physical Space: Planning Environments for Young Children". Washington, D.C.: National Association for the Education of Young Children, 1969

[14] T. D Wachs "The Nature of the Physical Microenvironment: An Expanded Classification System", Merill-Palmer Quarterly ,1989, pp 163-178.

[15] P. C. Lippman, Evidence Based Design for Elementary and Secondary Schools: A Responsive Approach to Creating Learning Environments. John Wiley \& Sons, NJ, 2010.

[16] R. G. Tharp \& R. Gallimore, Rousing Minds to Life: Teaching and Learning in Context. Cambridge University Press, New York, 1997.

[17] PEHKA Unpublished Responsive Research Report. Projects for Environmental Health Knowledge and Action, Inc. http://pehka.org/, Access Date: 20, June 2015.

[18] P. C. Lippman, The Spaces in Between, http://pubs.royle.com/article/The+Spaces+in+Between/195 8102/0/article.html) Learning by Design, Spring 2015, Acess Date: 25, October, 2015.

[19] T.D. Wachs., \& G.E Gruen, Early Experience and Human Development. New York: Plenum, 1982. 